\title{
BMJ Open Scientific, professional and experiential validation of the model of preventive behaviours at work: protocol of a modified Delphi Study
}

\author{
Alexandra Lecours
}

To cite: Lecours A. Scientific, professional and experiential validation of the model of preventive behaviours at work: protocol of a modified Delphi Study. BMJ Open 2020;10:e035606. doi:10.1136/ bmjopen-2019-035606

- Prepublication history for this paper is available online. To view these files, please visit the journal online (http://dx.doi. org/10.1136/bmjopen-2019035606).

Received 08 November 2019 Revised 01 August 2020 Accepted 06 August 2020
Check for updates

(C) Author(s) (or their employer(s)) 2020. Re-use permitted under CC BY-NC. No commercial re-use. See rights and permissions. Published by BMJ.

Department of Rehabilitation, Université Laval, Québec, Québec, Canada

Correspondence to Dr Alexandra Lecours; Alexandra.Lecours@fmed. ulaval.ca

\section{ABSTRACT}

Introduction To offer an in-depth understanding of preventive behaviours, those complex behaviours considered as levers to foster work prevention, recent theoretical and empirical studies permitted to develop the model of preventive behaviours at work. The next step is to validate the model with researchers, professionals and workers. This article aims to describe the study protocol that will be used to validate the model of preventive behaviours at work.

Methods and analysis This Delphi Study proposes seven systematic steps to conduct a scientifically rigorous validation study based on scientific and professional experts' opinion. A focus group to collect workers' opinion about the model has also been included in the protocol. Thirty experts (researchers and professionals) will be selected regarding their experience (eg, at least 5 years of experience) and expertise (eg, having published at least one article as the first author in the last 3 years) towards workers' health or organisational behaviours. Workers will be recruited to have a diversity in terms of age, gender and working conditions. Quantitative data will be analysed to calculate the percentage of experts' agreement on four content validity indicators (ie, comprehensiveness, representativeness, relevance and clarity). Qualitative data will be examined through a thematic analysis strategy. Ethics and dissemination Approval of the research ethics board of the Centre intégré universitaire de santé et de services sociaux de la Capitale Nationale has been obtained. Findings will be shared with various stakeholders inclusive of researchers, professionals and workers. Findings will be disseminated in workshops, peer-reviewed journals and conferences.

\section{INTRODUCTION}

The number of people in employment is growing in industrialised societies. For example, the Canadian labour force grew from 15.8 to 20.2 million workers between 2000 and 2019, which represents an increase of near than $28 \% .^{1}$ Recognised as a determinant of health, ${ }^{2}{ }^{3}$ work may have positive effects on the health, safety and well-being of people, as it may contribute to financial health, social recognition or protection

\section{Strengths and limitations of this study}

- The proposed method includes scientific, professional and experiential knowledge, which is innovative and timely.

- An entire research step is dedicated to the involvement of the public, this maximising the relevance of the study results.

- The proposed research design does not permit obtaining a statistical validation of the model of preventive behaviours at work; further studies are required.

against declining skills. ${ }^{4}$ When a work-related health problem occurs, whether it is an accident, a physical illness or a transient mental disorder, the negative consequences are harmful not only for workers and families, but also for work organisations, by reducing performance and productivity. ${ }^{5}$ The societal impacts are also impressive with an estimated amount of over US $\$ 250$ billion in the USA to cover annual costs related to work-related health problems. ${ }^{6}$

It is then important to focus on the determinants of workers' health, safety and wellbeing. The literature suggests that factors related to healthcare services, compensation systems, work organisations as well as to workers themselves would influence the prevention of the occurrence, relapse and prolonged disability related to work-related health problems. ${ }^{7-9}$ Considering workerrelated factors, the preventive behaviours they may adopt would play an important role in workplace health, safety and well-being. ${ }^{10-13}$ Indeed, the influence of these behaviours on the risk of work-related health problems has been demonstrated in several studies conducted with various workers' populations. ${ }^{101415}$ Considered as levers to promote workers' health, safety and well-being, these preventive behaviours are complex, and the 
literature lacks a concrete definition of them. ${ }^{16}$ To offer an in-depth understanding of preventive behaviours, recent theoretical and empirical studies have permitted proposing the model of preventive behaviours at work. ${ }^{16}$ This model defines the behaviours workers may adopt to foster health, safety and well-being at work.

The model shows six major preventive behaviours, which are (1) adopting a reflective practice (eg, analysing work situations, identifying risks and taking decisions about one's health); (2) complying with rules and procedures (eg, respecting work-related procedures or wearing personal protective equipment), (3) participating, involving and taking initiatives for prevention (eg, involving in health and safety committees or seeking help from available resources), (4) caring about others (eg, team working or listening to each other), (5) communicating (eg, expressing one's needs or limits) and (6) adopting a healthy lifestyle (eg, having lifestyle balance or exercising).

The model of preventive behaviours at work presents a systemic and multifactorial view of preventive behaviours. These behaviours are largely influenced by contextual factors related to workers themselves, occupation of work or environment. These contextual factors have an impact on the ability of workers to engage in preventive behaviours. Thus, in addition to being interested in the concrete behaviours, the model focuses on the factors upstream of the manifestation of a behaviour, on the context in which workers adopt behaviours. The model also considers the consequences following the manifestation of behaviours. These consequences are generally positive for workers themselves (eg, health, safety and well-being) as well as for the organisation (eg, work climate). The model reflects the dynamic interaction and multiple influences between (1) contextual factors, (2) workers' engagement in preventive behaviours (3) and outcomes. This model was developed after conducting three theoretical ${ }^{17}$ and empirical ${ }^{18-20}$ studies. The development process and visual representation of the model are detailed elsewhere. ${ }^{16}$

Regarding occupational health, several of the current models focus only on one aspect of the health of workers, whether physical ${ }^{17}$ or mental. ${ }^{21}$ In accordance with the vision of health proposed by WHO, ${ }^{22}$ the model of preventive behaviours at work suggests a holistic vision of the health of workers, inclusive of the physical, mental and social aspects. This holistic understanding of health reflects in contextual factors, preventive behaviours and outcomes. In addition, the focus of the model rests on the engagement of workers in preventive behaviour at work. This angle is innovative since most of the current models focus on the actions the organisation may have on workers' health, ${ }^{23}$ giving them a mostly passive role. Since the management of occupational health, safety and wellbeing must be shared by everyone involved in an organisation, ${ }^{24-27}$ this model helps to better explain the active role workers may have. Designed to be applicable to the reality of workers, regardless of the nature of their work or health, this model can also help to understand the factors that influence workers' engagement in preventive behaviours and the resulting effects on health, safety and well-being.

To increase its scientific validity, to maximise its use in professional settings and ultimately to foster workers' health, safety and well-being, the next step is to validate the model. The literature offers a large spectrum of conceptual model validation study designs. Over the years, the Delphi technique has been used in various validation studies, but most of the published articles focused on results, while validation protocols remain more or less detailed, making difficult replicating studies. Furthermore, authors have criticised the lack of clear guidelines in the current writing surrounding the use of the Delphi technique, which may lead to a lack of scientific rigour. ${ }^{28} 29$ To fill these gaps, the aim of this article is to describe the study protocol that will be used to validate the model of preventive behaviours at work.

\section{METHOD AND ANALYSIS \\ Design}

Created in the middle of the 18th century ${ }^{30}$ and used in health sciences since the $1970 \mathrm{~s},{ }^{31}$ the Delphi technique is recognised as an efficient way to structure communication processes allowing individuals to work on a complex subject, ${ }^{32}$ which is the case of the model of preventive behaviours at work. Since this model is emerging, a first step of validation with experts will make it possible to appreciate its acceptability ${ }^{29}$ from the scientific community and its applicability from the knowledge users, which are professionals and workers. The main advantage of the Delphi technique is that communications take place remotely, allowing the recruitment of experts from all over the planet. ${ }^{2833}$ Disadvantages noted in the scientific literature relate to the lack of consensus on the definition of an expert and on how to rule on the consensus' adoption. ${ }^{33-35}$ The limited implication of knowledge users in Delphi Studies is also a weak point of the actual method. ${ }^{29}$ The method can also take a considerable amount of time from the participants, which can discourage them from getting involved. ${ }^{28} 3136$ Finally, many variants of the original method have been used in published studies, ${ }^{29}$ but lack of justification for the changes made and lack of details in protocols contribute to creating ambiguities in the guidelines to follow. ${ }^{28}{ }^{29}$ Our wish in drafting this protocol is to bring clarity to these elements of the study design.

\section{Procedure and analysis}

The Delphi technique will be used to obtain consensus from scientific, professional and experiential experts on content validity indicators, which are: (1) comprehensiveness of the model structure, (2) representativeness to the content domain, (3) relevance of the model components and (4) clarity of the model components and links. These indicators were recommended according to writing on 


\begin{tabular}{ll}
\hline Table 1 & Systematic steps of the study design \\
\hline Step 1 & $\begin{array}{l}\text { Elaborate selection criteria for scientific and } \\
\text { professional experts }\end{array}$ \\
Step 2 & Make scientific and professional experts list \\
Step 3 & Contact scientific and professional experts \\
Step 4 & Administrate questionnaires \\
Step 5 & Synthesise answers \\
Step 6 & Consult experiential experts \\
Step 7 & Final analysis and publication
\end{tabular}

content validity. ${ }^{37-40}$ The study design proposes seven systematic steps to conduct a scientifically rigorous validation study (see table 1). The expected duration of the study is 12 months, beginning in the summer 2020 .

To validate the model according to (a) scientific, (b) professional and (c) experiential expertise, participants from the following three categories will be recruited: (a) researchers, (b) professionals and (c) workers. The boundaries between these expertises are, however, permeable; the experts will be invited to give their opinion on the various indicators according to their overall expertise. For example, even if professionals are recruited on the basis of their technical and specialised experience with workers, it is also possible that scientific or experiential knowledge influence their contribution. It is hoped that this validation study will be carried out using rich and diversified expertise.

\section{Elaborate selection criteria for scientific and professional experts}

The quality of a study using the Delphi technique mainly rests on the choice of experts. ${ }^{29} 3641$ Indeed, since the opinion of these will serve to generate the results of the study, their selection must be judicious. Currently, there is no recognised definition of 'who is an expert' and no universal criteria for structuring the choice of experts. ${ }^{33-35}$ The researcher's judgement is solicited to determine criteria that will enable her/him to select the people most likely to contribute to meeting the research objective. $^{283536}$

The first steps of the protocol imply to select researchers and professionals. A list of inclusion criteria was established based on information available in the scientific literature.

\section{Researchers}

Expertise seems to be the main criteria to select researchers. ${ }^{36}$ For the success of a Delphi Study, experts must have a thorough knowledge of the subject. ${ }^{42}$ For the current study, researchers with expertise in the field of workers' health or organisational behaviours will be targeted. It will be possible to select experts in various disciplines such as industrial psychology, ergonomics, occupational therapy, occupational medicine or human resource management because the model of preventive behaviours at work was developed according to that literature. $^{16}$
To select researchers, the evaluation of the relevance of their published scientific papers related to the subject of our study will be used. This systematic selection method is cited in many manuscripts. ${ }^{35} 4344$ A researcher will be identified to be part of the panel of experts if she/he has published at least one relevant article, as the first author, in the last 3 years. ${ }^{45}$ This published article should specifically concern prevention at work.

\section{Professionals}

Since the model of preventive behaviours at work is expected to be used in practical settings, we chose to include professionals in the validation process. Although some authors do not recommend including the participation of professionals for emerging concept validation, ${ }^{41}$ the literature in the field of health mostly recommends including professionals in the panel of experts. ${ }^{3446-48}$

Work experience in the field of study seems to be the criterion most often used to select professionals. ${ }^{42}$ For our study, a variety of professionals (ie, ergonomists, industrial psychologists, occupational therapists, occupational physicians or human resources managers) will be recruited if they have at least 5 years of experience in relation with workers.

\section{Make scientific and professional experts list}

To recruite researchers based on their published articles, the following scholarly journals will be consulted: (a) Work, (b) Journal of Occupational and Organizational Psychology and (c) Safety Science. These journals are targeted because of their readership profile, the number of researchers contributing to it and the topics that are relevant to our research project. ${ }^{41}$ Indeed, these journals have a wide vision of the thematic of work and include articles from various disciplines and fields of research. The journal numbers published in the last 3 years will be consulted one by one. The articles that seem to have a link with the subject of study according to their title and keywords will be retained. The abstract of these articles will then be read to confirm the author's relevance to the research project. If needed, the ResearchGate and personal web pages of researchers will be consulted to deepen the analysis and make sure of their potential contribution to this validation study. For feasibility reasons, only three journals will be extensively screened. However, each of the experts identified in this first screening step will be invited to suggest other potential experts during the first contact. If those suggested experts meet the inclusion criteria, they will be added to the list of potential experts. This second selection step using the snowball method will allow identifying experts who can contribute validating the model, even if they have not published articles in the targeted journals.

Recruitment of professionals will be done in two stages. First, participants meeting the inclusion criteria will be identified in the author's network. Subsequently, the snowball method will be used to expand the pool of experts. 
Particular attention will be paid to recruiting experts of different ages, genders, work environments and geographic origins. An Excel table will be constructed to gather relevant information about potential experts, such as the level of training, area of expertise, affiliation, email address and country. ${ }^{41}$

The number of experts to recruit is not established in the actual literature. ${ }^{36}{ }^{46}$ Even if some Delphi Study were conducted with more than 1500 participants, ${ }^{31}$ they mainly include 10-20 participants. ${ }^{36} 49$ The size of the group has an importance for the stability of the results. Indeed, with a smaller group, an expert has a greater influence on the result since her/his opinion occupies a larger proportion of the consensus. ${ }^{46}$ On the other hand, it is more complex and costly to consult with a large number of experts. ${ }^{28} 36$

For our study, we plan to recruit 30 experts: 15 researchers and 15 professionals. Considering the attrition of participants during the study, this number seems adequate.

\section{Contact scientific and professional experts}

After having made a list of potential experts to recruit for the consultation, it is time to invite them. Nowadays, email seems to be the most frequent way to contact experts. Authors suggest sending a detailed message to invite experts. ${ }^{28} 3334414750$ The message will contain the following information: presentation of the researcher responsible of the study, description of the study, reasons for the selection of the expert, procedures to be followed to participate to the consultation, estimation of the time required, expectations regarding the expert (including the importance of participating in all the rounds of the consultation), promise of anonymity and participation recognition. ${ }^{283334414750}$

\section{Administrate questionnaires}

The first questionnaire allows experts to express their opinion on the subject to study. ${ }^{29}$ The purpose of this first questionnaire is often to provide an overview of the experts' opinion on the subject of study, and then to determine the elements to be studied in the subsequent questionnaires. Basic open-ended questions are required to cover the entire subject. ${ }^{34} 4651$ Since these open-ended questions are likely to generate a great deal of information, ${ }^{51}$ it is suggested to limit the number of questions in this first questionnaire. ${ }^{29}{ }^{30}$ For example, the first questionnaire of our consultation will contain four large questions about the indicators of content validity (ie, comprehensiveness, representativeness, relevance and clarity) in relation with the model of preventive behaviours at work and its components. As suggested in the literature, we will also add a fifth question to permit experts to freely add information they find relevant about the subject. ${ }^{29}$ In order to ensure the questionnaire clarity, a pretest will be done with four experts (two researchers and two professionals), as suggested by many authors who published about the Delphi technique. ${ }^{28} 313452$ The qualitative data gathered with this first questionnaire will be analysed with a thematic analysis strategy using the QDA Miner software. This will permit to determine the content of the subsequent consultation rounds.

The second questionnaire (and the following, if applicable) will first summarise the opinions found in the previous questionnaire. ${ }^{36}$ After that, the idea is to document experts' opinion on more specific elements, generally with closed questions. ${ }^{34}$ The opinion will often be documented using Likert-type scales, with the aim to obtain a consensus of experts. ${ }^{36}$ For example, elements related to the four content validity indicators that emerged from the analysis of the first questionnaire will be assessed by experts on a 4-point Likert scale (eg, clarity : 1-this element is not clear, 2-this element needs major revisions to be clear, 3-this element needs minor revisions to be clear and 4-this element is clear). The iteration process and the return on the information offered to the experts will allow them to reconsider their opinion in the light of that of the others, thus convince toward a consensus. The anonymity provided by the method facilitates this process. ${ }^{53}$ The quantitative data gathered with the administration of the second questionnaire, and the following, will be analysed with descriptive statistics, using the IBM SPSS Statistics Version 26 software.

Nowadays, web questionnaires are preferred to postal ones. ${ }^{29}$ We will also follow this tendency in our study.

\section{Synthesise answers}

This research step comprises the crucial moment of the determination of the consensus of experts about the different components of the model of preventive behaviours at work. Paradoxically, the literature does not offer a consensus about the definition of the consensus. ${ }^{28} 31334652$ The consensus, which is the agreement between the experts, may be defined in different ways, such as a measure of central tendency of experts' quantitative responses, the stability in experts' responses between the rounds of consultation or a subjective measure of general opinion. ${ }^{54}$ Given the lack of a clear rule on the definition of consensus, it is important for researchers conducting a Delphi Study to define this agreement in an operational manner before starting the consultation. ${ }^{29} 55$ The chosen definition of the consensus is to impact on the number of required rounds to obtain this agreement between the experts.

Using a percentage of agreement would be the most common way to rule on consensus. ${ }^{31}$ However, the percentage to be reached to obtain a consensus varies considerably across studies, ranging from $51 \%$ to $100 \%{ }^{28313336}$ A $100 \%$ consensus may be impossible to achieve, and often not necessary. ${ }^{33}$ Although aiming to reach a high percentage of agreement permits to ensure the agreement between the experts, it may result in the need to add several consultation rounds. To have a sufficiently discriminating percentage without excessively lengthening the time of realisation of the study, we will set it at $80 \%$. We will use the following rules to monitor consensus: (a) if $80 \%$ of experts give an element the 


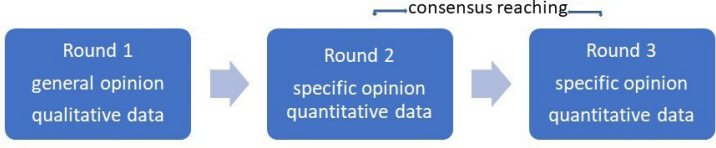

Figure 1 Description of rounds of consultation.

rating of 4 on the 4-point Likert scale, we consider that a consensus was obtained on this element and it will be kept in the model; (b) if $80 \%$ of experts give an element the rating of 1 on the 4-point Likert scale, we consider that a consensus was obtained on this element and it will be removed from the model; (c) for elements having mostly been rated 2 or 3 on the 4-point Likert scale, modification will be made according to experts' opinion and these elements will be submitted to the following round of consultation.

The literature suggests that two or three rounds are needed to reach the consensus. ${ }^{33}$ A priori, we plan to do three rounds, as shown in figure 1. We will give experts 2 weeks to answer a questionnaire, as suggested by others. ${ }^{36}{ }^{56-58}$ The total time to complete the collection of data can, therefore, be spread out over a few weeks depending on the number of rounds to be made.

\section{Consult experiential experts}

A last consultation step will be conducted with experiential experts, namely workers in this study. While not common in Delphi Studies, this decision to include people having experienced a condition has been suggested by other authors who had conducted health-related studies. ${ }^{3159-61}$ This permits to favour the involvement of a variety of stakeholders.

The consultation will take the form of a focus group. ${ }^{62}$ The purpose of the consultation will be to verify the applicability of the results obtained, the relevance with the current work context and the face validity of the model.

Groups of eight workers will be formed. This number of participants per group is large enough to get rich discussions ${ }^{62}$ and small enough to let all participants express themselves. ${ }^{63}$ Participants will be recruited to have a diversity in terms of ages, genders and working conditions (eg, type of work, full time vs part time, and so on). In a 2-hour discussion, results of the consultation with scientific and professional experts will be exposed to workers. Different indicators will be discussed, such as facilitators and obstacles for the usability of the model or relevance of its components to the reality of workers. The group facilitation guide will be developed for the purpose of this study and validated by a pretest with two people having the same characteristics as the participants. The number of groups to be conducted will be defined throughout the study until data reveals a redundancy in the meaning of the ideas shared by the participants. ${ }^{64}$ It is estimated that two or three groups will be required to reach data saturation. ${ }^{65}$ After fully transcribing the data and importing it into the QDA Miner software, a thematic analysis strategy in four stages will be followed ${ }^{66}$ : (1) repeated readings of the data corpus to develop a feeling of immersion; (2) initial coding (descriptive codes 'in vivo' will be assigned to the meaning units found in the corpus); (3) conception of a code tree (the codes (microlevel) will be grouped into categories (mesolevel) and/or themes (macrolevel)) and (4) finalisation of the code tree by going back and forth between the raw data and the general structure to clarify and interpret the data while respecting the experience of the participants. To ensure scientific rigour, the thematic analysis process will be carried out by two people and the interjudge agreement will be periodically checked. This last consultation step will provide nuances to the study results.

\section{Final analysis and publication}

Once the analysis of all collected data and the consensus reached, a summary of the results will be transmitted to each expert who took part in the study, namely the researchers, the professionals and the workers. The experts will be free to comment on these findings, which may help to enhance reflection about the validity of the model of preventive behaviours at work.

\section{Patient and public involvement}

To support coproduction of knowledge, this study proposes to actively involve various stakeholders in the different steps. In fact, professional experts' opinion will be gathered by questionnaire to confirm or improve the model. As these persons will be likely to use the model in their practice, building the study around their opinion will improve the relevance of the model and increase the likelihood that it will be used to guide interventions about preventive behaviours at work. Stakeholders will also be involved in the recruitment of participants using the snowball method. The protocol also proposes to add an innovative and timely step to the validation process using the Delphi technique. In fact, the consultation step with experiential experts, namely workers in this study, will allow including the perceptions and experiences of the public in the interpretation of results.

\section{ETHICS AND DISSEMINATION}

Approval of the research ethics board of the Centre intégré universitaire de santé et de services sociaux de la Capitale Nationale has been obtained (project 20201919). The preponderant involvement of various stakeholders throughout the study will offer the possibility of start disseminating results during conducting the study. Following that, diverse activities will take place to transfer knowledge. For examples, scientific papers will be published, and conferences held to share results with researchers. Workshops will be organised with professionals. Popular science conferences are also planned to disseminate the results of the study to the general public.

Acknowledgements The author thanks Guylain Breton, research trainee, for his help with the literature search.

Contributors AL drafted the manuscript, made the required revisions and approved the final version of the manuscript. 
Funding This work was supported Fonds d'établissement de jeune chercheur from the Center for Interdisciplinary Research in Rehabilitation and Social Integration (IS120195).

\section{Competing interests None declared.}

Patient and public involvement Patients and/or the public were involved in the design, or conduct, or reporting, or dissemination plans of this research. Refer to the Methods section for further details.

Patient consent for publication Not required.

Provenance and peer review Not commissioned; externally peer reviewed.

Open access This is an open access article distributed in accordance with the Creative Commons Attribution Non Commercial (CC BY-NC 4.0) license, which permits others to distribute, remix, adapt, build upon this work non-commercially, and license their derivative works on different terms, provided the original work is properly cited, appropriate credit is given, any changes made indicated, and the use is non-commercial. See: http://creativecommons.org/licenses/by-nc/4.0/.

ORCID iD

Alexandra Lecours http://orcid.org/0000-0002-4485-7829

\section{REFERENCES}

1 Statistics Canada. Labour force characteristics by Province, monthly, seasonally adjusted, 2019. Available: https://www150.statcan.gc.ca/ t1/tbl1/fr/cv.action?pid=1410028703\#timeframe

2 OMS. Charte d'Ottawa pour La promotion de la santé. Ottawa, 1986.

3 Wilcock AA, Hocking C. An occupational perspective of health. In: Thorofare NJ, ed. 3rd edn. USA: SLACK Incorporated, 2015.

4 Bosma H, van Boxtel MPJ, Ponds RWHM, et al. Education and agerelated cognitive decline: the contribution of mental workload. Educ Gerontol 2003;29:165-73.

5 Demerouti E, Bakker AB, Halbesleben JRB. Productive and counterproductive job crafting: a daily diary study. $J$ Occup Health Psychol 2015;20:457-69.

6 Leigh JP. Economic burden of occupational injury and illness in the United States. Milbank Q 2011;89:728-72.

7 Robichaud M-M. Retour au travail la suite d'une lésion professionnelle : perspective des intervenants en réadaptation du système d'indemnisation public. Université Laval, 2016.

8 Durand M-J, Loisel P, Hong QN, et al. Helping clinicians in work disability prevention: the work disability diagnosis interview. J Occup Rehabil 2002:12:191-204.

9 Loisel P, Durand M-J, Berthelette D, et al. Disability prevention. Disease Manag Health Outcomes 2001;9:351-60.

10 Roy M, Cadieux J, Forter L, et al. Validation d'un outil d'autodiagnostic et d'un modèle de progression de la mesure en santé et sécurité du travail. Montréal: IRSST, 2008.

11 Akselsson R, Jacobsson A, Bötjesson M, et al. Efficient and effective learning for safety from incidents. Work 2012;41:3216-22.

12 Simard M, Marchand A. The behaviour of first-line supervisors in accident prevention and effectiveness in occupational safety. Saf Sci 1994;17:169-85.

13 Cossette R. Le comportement sécuritaire, un modèle qui pourrait rallier deux écoles de pensée. Travail et Santé 2013;29:6-9.

14 Roy M, Desmarais L, Cadieux J. Améliorer la performance en SST : les résultats vs les prédicteurs. Pistes 2005;7.

15 Johnson SE. The predictive validity of safety climate. J Safety Res 2007:38:511-21.

16 Lecours A. Using an occupational perspective to understand behaviours fostering the prevention of work-related health problems: a proposed conceptual model. J Occup Sci 2020;27:222-35.

17 Lecours A, Therriault P-Y. Preventive behaviour at work - a concept analysis. Scand J Occup Ther 2017;24:249-58.

18 Lecours A, Therriault P-Y. Habiliter les travailleurs la prévention: description des pratiques des ergothérapeutes visant la mise en place des antécédents du comportement préventif au travail. Revue francophone de recherche en ergothérapie 2019;5:59-79.

19 Lecours A, Therriault P-Y. Development of preventive behavior at work: description of occupational therapists' practice. Work 2018;61:477-88.

20 Lecours A, St-Hilaire F, Daneau P. How to move toward an integrated prevention approach in mental health at work? Promoting workers' commitment through concrete actions; In press.

21 Demerouti E, Bakker AB, Nachreiner F, et al. The job demandsresources model of burnout. J Appl Psychol 2001;86:499-512.
22 OMS. Préambule La constitution Conférence internationale sur La Santé. New York, 1946.

23 Siegrist J. Adverse health effects of high-effort/low-reward conditions. J Occup Health Psychol 1996;1:27-41.

24 Lowe GS. Creating healthy organizations: how Vibrant workplaces inspire employees to achieve sustainable success. University of Toronto Press, 2010.

25 Shain M, Kramer DM. Health promotion in the workplace: framing the concept; reviewing the evidence. Occup Environ Med 2004:61:643-8.

26 OMS. Plan d'action mondiale pour la santé des travailleurs 20082017. In: Soixantième assemblée mondiale de la santé. 12, 2007.

27 Éditeur officiel du Québec. Loi sur La santé et La sécurité du travail. Québec: Gouvernement du Québec, 2017.

28 Vernon W. The Delphi technique: a review. Int J Ther Rehabil 2009;16:69-76.

29 Tremblay-Boudreault V, Dionne CE, Delphi L. Application dans la conception d'un outil clinique en réadaptation au travail en santé mentale. In: Corbière $\mathrm{M}$, Larivière $\mathrm{N}$, eds. Méthodes qualitatives, quantitatives et mixtes. Québec: Presses de l'Université Du Québec, 2014: 283-303.

30 Couper MR. The Delphi technique: characteristics and sequence model. ANS Adv Nurs Sci 1984;7:72-7.

31 Powell C. The Delphi technique: myths and realities. J Adv Nurs 2003;41:376-82.

32 Linstone HA, Turoff M. The Delphi method: addison-Wesley reading, 1975.

33 McPherson S, Reese C, Wendler MC. Methodology update: Delphi studies. Nurs Res 2018;67:404-10.

34 Hohmann E, Cote MP, Brand JC. Research pearls: expert consensus based evidence using the Delphi method. Arthroscopy 2018;34:3278-82.

35 Baker J, Lovell K, Harris N. How expert are the experts? An exploration of the concept of 'expert' within Delphi panel techniques. Nurse Res 2006;14:59-70.

36 Hsu C-C, Sanford BA. The Delphi technique: making sense of consensus. Pract Assess Res Eval 2007;12.

37 Grant JS, Davis LL. Selection and use of content experts for instrument development. Res Nurs Health 1997;20:269-74.

38 Polit DF, Beck CT. The content validity index: are you sure you know what's being reported? critique and recommendations. Res Nurs Health 2006;29:489-97.

39 Lynn MR. Determination and quantification of content validity. Nurs Res 1986;35:382-6.

40 Rubio DM, Berg-Weger M, Tebb SS, et al. Objectifying content validity: conducting a content validity study in social work research. Soc Work Res 2003;27:94-104.

41 Ekionea J-PB, Bernard P, Plaisent M. Consensus par La méthode Delphi sur les concepts clés des capacités organisationnelles spécifiques de la gestion des connaissances. Recherche Qualitat 2011;29:168-92.

42 Ford TE. A national Delphi study examining the feasibility of universal access to health and medical care in the United States. University of La Verne, 2002.

43 Zerem E. The ranking of scientists based on scientific publications assessment. J Biomed Inform 2017;75:107-9.

44 Steurer J. The Delphi method: an efficient procedure to generate knowledge. Skeletal Radiol 2011;40:959-61.

45 Graham B, Regehr G, Wright JG. Delphi as a method to establish consensus for diagnostic criteria. J Clin Epidemiol 2003;56:1150-6.

46 Jorm AF. Using the Delphi expert consensus method in mental health research. Aust N Z J Psychiatry 2015;49:887-97.

47 Dari T H. Development and validation of community-based participatory research competencies: a Delphi study [Dissertation]. University of Toledo, 2017.

48 Wendimagegn NF, Bezuidenhout M. The integrated health service model: the approach to restrain the vicious cycle to chronic diseases. BMC Health Serv Res 2019;19:347.

49 Hara Y. Brain plasticity and rehabilitation in stroke patients. J Nippon Med Sch 2015;82:4-13.

50 Hasson F, Keeney S, McKenna H. Research guidelines for the Delphi survey technique. J Adv Nurs 2000;32:1008-15.

51 Cwalina AM. Organizational practices leading to a positive safety culture : a Delphi approach [Dissertation]. Nova Southeastern University, 2013

52 Tremblay-Boudreault V, Dionne CE. L'approche Delphi : Application dans la conception d'un outil clinique en réadaptation au travail en santé mentale. In: Corbière $\mathrm{M}$, Larivière $\mathrm{N}$, eds. Méthodes qualitatives, quantitatives et mixtes: les Presses de l'Université de Québec, 2000. 
53 Jones J, Hunter D. Consensus methods for medical and health services research. BMJ 1995;311:376.

54 Holey EA, Feeley JL, Dixon J, et al. An exploration of the use of simple statistics to measure consensus and stability in Delphi studies. BMC Med Res Methodol 2007;7:52.

55 Keeney S, Hasson F, McKenna H. Consulting the oracle: ten lessons from using the Delphi technique in nursing research. J Adv Nurs 2006;53:205-12.

56 Cole ZD, Donohoe HM, Stellefson ML. Internet-based Delphi research: case based discussion. Environ Manage 2013;51:511-23.

57 Toronto CE, Coleen E. Health literacy competencies for registered nurses: an e-Delphi study. J Contin Educ Nurs 2016;47:558-65.

58 Harper MG, Asselin ME, Kurtz AC, et al. Research priorities for nursing professional development: a modified e-Delphi study. $J$ Nurses Staff Dev 2012;28:137-42.

59 Lakeman R. Mental health recovery competencies for mental health workers: a Delphi study. J Ment Health 2010;19:62-74.

60 Green HK, Smith E, Poole R, et al. A Delphi study of the subjective "rush" experience: Understanding the perspective of the injecting drug user to enhance quality of drug intervention. $J$ Subst Use 2009; 14:295-305.

61 Arblaster K, Mackenzie L, Matthews L, et al. Learning from consumers: an eDelphi study of Australian mental health consumers' priorities for recovery-oriented curricula. Aust Occup Ther $J$ 2018;65:586-97.

62 Desrosiers J, Larivière N. Le groupe de discussion focalisé. In: Corbière $\mathrm{M}$, Larivières $\mathrm{N}$, eds. Méthodes qualitatives, quantitatives et mixtes. Québec: Presses de l'Université du Quénec, 2014: 257-81.

63 Onwuegbuzie AJ, Dickinson WB, Leech NL, et al. A qualitative framework for collecting and analyzing data in focus group research. Int J Qual Methods 2009;8:1-21.

64 Barbour R. Doing focus groups. Sage, 2008.

65 Guest G, Namey E, McKenna K. How many focus groups are enough? building an evidence base for nonprobability sample sizes. Field methods 2017;29:3-22.

66 Paillé P, Mucchielli A. L'analyse qualitative en sciences humaines et sociales. 4th edn. Paris: Armand Colin, 2016. 